\title{
Therapeutic potential of Moringa oleifera leaves in chronic hyperglycemia and dyslipidemia: a review
}

\author{
Majambu Mbikay ${ }^{1,2 *}$ \\ ${ }^{1}$ Chronic Disease Program, Ottawa Hospital Research Institute, Ottawa, ON, Canada \\ 2 Department of Biochemistry, Microbiology and Immunology, Faculty of Medicine, University of Ottawa, Ottawa, ON, Canada
}

\section{Edited by:}

Adolfo Andrade-Cetto, Universidad Nacional Autónoma de México,

Mexico

Reviewed by:

Adolfo Andrade-Cetto, Universidad Nacional Autónoma de México,

Mexico

Rene Cardenas, Universidad Nacional

Autónoma de México, Mexico

\section{${ }^{*}$ Correspondence:}

Majambu Mbikay, Ottawa Hospital

Research Institute, Civic Campus, 725

Parkdale Avenue, Ottawa, ON,

Canada K1Y $4 E 9$.

e-mail:mmbikay@ohri.ca
Moringa oleifera (M. oleifera) is an angiosperm plant, native of the Indian subcontinent, where its various parts have been utilized throughout history as food and medicine. It is now cultivated in all tropical and sub-tropical regions of the world. The nutritional, prophylactic, and therapeutic virtues of this plant are being extolled on the Internet. Dietary consumption of its part is therein promoted as a strategy of personal health preservation and self-medication in various diseases. The enthusiasm for the health benefits of $M$. oleifera is in dire contrast with the scarcity of strong experimental and clinical evidence supporting them. Fortunately, the chasm is slowly being filled. In this article, I review current scientific data on the corrective potential of $M$. oleifera leaves in chronic hyperglycemia and dyslipidemia, as symptoms of diabetes and cardiovascular disease (CVD) risk. Reported studies in experimental animals and humans, although limited in number and variable in design, seem concordant in their support for this potential. However, before M. oleifera leaf formulations can be recommended as medication in the prevention or treatment of diabetes and CVD, it is necessary that the scientific basis of their efficacy, the therapeutic modalities of their administration and their possible side effects be more rigorously determined.

Keywords: Moringa oleifera, cardiovascular disease, diabetes, phytotherapy, natural products

\section{INTRODUCTION}

Moringa oleifera, Lam (M. oleifera), also known as Moringa pterygosperma Gaertn, is a member of the Moringaceae family of perennial angiosperm plants, which includes 12 other species (Olson, 2002). Native of the sub-Himalayan northern parts of India, it is cultivated throughout tropical and sub-tropical areas of the world, where it is known by various vernacular names (Ramachandran et al., 1980), with drumstick tree, horseradish tree, and malunggay being the most commonly found in the literature.

Moringa oleifera is an edible plant. A wide variety of nutritional and medicinal virtues have been attributed to its roots, bark, leaves, flowers, fruits, and seeds (Ramachandran et al., 1980; Anwar et al., 2007; Kumar et al., 2010). Phytochemical analyses have shown that its leaves are particularly rich in potassium, calcium, phosphorous, iron, vitamins $\mathrm{A}$ and $\mathrm{D}$, essential amino acids, as well

\footnotetext{
Abbreviations: ACP, acid phosphatase; ALP, alkaline phosphatase; ALT, alanine aminotransferase; AST, aspartate amino transferase; AUC, area under the curve; bw, body weight; CAD, coronary artery disease; CVD, cardiovascular disease; DM, diabetes mellitus; FPG, fasting blood glucose; GIT, gastrointestinal tract; GK, GotoKakizaki; $\mathrm{HbA}_{1 \mathrm{c}}$, glycated hemoglobin; HCD, high-cholesterol diet; HDL, highdensity lipoprotein; HFD, high-fat diet; IL, interleukin; IPGTT, intraperitoneal glucose tolerance test; LDL, low-density lipoprotein; LDLR, LDL receptor; NEFA, non-esterified fatty acid, OGTT, oral glucose tolerance test; oxLDL, oxidized LDL; PCSK9, proprotein convertase, subtilisin/kexin-type 9; PPPG, post-prandial blood glucose; PVC, packed cell volume; ROS, reactive oxygen species; SREBP, sterol regulatory element-binding protein; STZ, streptozotocin; T2DM, type-2 diabetes mellitus; TG, triglyceride; TNF, tumor necrosis factor; VLDL, very low-density lipoprotein; VSMC, vascular smooth muscle cell; WBC, white-blood cell.
}

as such known antioxidants such as $\beta$-carotene, vitamin $C$, and flavonoids (Bennett et al., 2003; Aslam et al., 2005; Manguro and Lemmen, 2007; Amaglo et al., 2010; Gowrishankar et al., 2010).

The therapeutic use of $M$. oleifera parts in the Indian subcontinent dates back to Antiquity. In other parts of the world, in sub-Saharan Africa in particular, such a use appears not to have been known by the wide public, as it is being promoted by diverse organizations as an untapped opportunity (Thurber and Fahey, 2009; Torimiro et al., 2009). At the writing of this manuscript (April 2011), a search on the Internet, using the Google browser and the words moringa, drumstick, or malunggay as keys within page titles, reported nearly 90,000 websites. Most of these sites present this plant as a remedy to malnutrition and a vast range of ailments. On the Internet, M. oleifera is variably labeled as Miracle Tree, Tree of Life, Mother's Best Friend, God's Gift to Man, Savior of the Poor. In many regions of Africa, it is widely consumed for self-medication by patients affected by diabetes, hypertension, or HIV/AIDS (Dieye et al., 2008; Kasolo et al., 2010; Monera and Maponga, 2010). Yet, in a similar search of the PubMed database of biomedical publications, merely 163 papers were fetched; $76 \%$ of them were published in the last decade (Figure 1). A similar search through Google Scholar produced about 1250 articles; the vast majority of these were in scientific journals not indexed in PubMed, and a good number in non-peer-reviewed book chapters, patents, citations, or other documents. By comparison, green tea, another plant claimed to be medicinal for a range of illnesses (Schneider and Segre, 2009), 1972 and 7240 publications were retrieved in a similar search in PubMed and Google Scholar, 


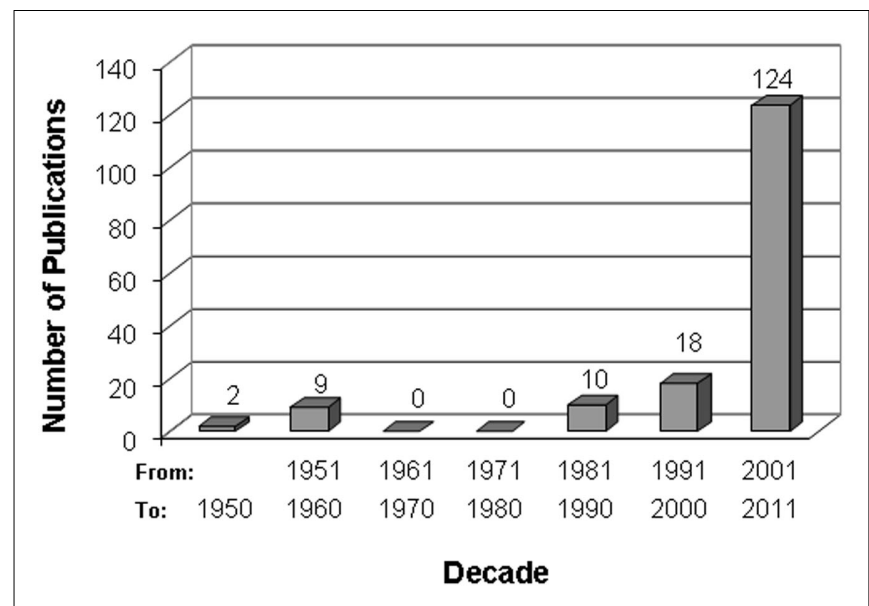

FIGURE 1 | Chronological trend of scientific publications on $\boldsymbol{M}$. oleifera. The bibliographic search was conducted online in the PubMed database at www.pubmed.ncbi.nlm.nih.org/, using moringa, drumstick, or malunggay as title keywords. Article abstracts were reviewed for content and those unrelated to $M$. oleifera were discarded. Of the 163 PubMed articles retained, 64 (39.3\%) were about the physiological effects of $M$. oleifera preparation in experimental animals, 30 (18.4\%) on their water-cleansing properties as toxic metal absorbent or flocculent, 23 (14.1\%) about their chemical composition, 22 (13.5\%) about their antimicrobial efficacy, 5 (3.1\%) about their antioxidant properties in vitro, 5 (3.1\%) about their effects on cellular physiology ex vivo, 6 (3.1\%) on their nutritional values, $3(1.8 \%)$ about their therapeutic effects in humans, and 6 about various matters (review, genetics, biofuel, animal feed).

respectively. Clearly, in spite of the widely held "belief" in the health benefits of $M$. oleifera, the interest of the international biomedical community in the medicinal potential of this plant has been rather tepid.

This report is a review of current data on the therapeutic potential of $M$. oleifera in chronic hyperglycemia and dyslipidemia. Chronic hyperglycemia is an indicator of diabetes mellitus (DM), and chronic dyslipidemia a risk factor for cardiovascular disease (CVD). These metabolic disorders are global epidemics (Yusuf et al., 2001; Wild et al., 2004). In developing countries, they are on the way to becoming as major causes of morbidity and mortality as infectious diseases, due to the progressive transition in these countries to a lifestyle characterized, among other aspects, by greater access to dietary calories and less demand for calorie expenditure (Hossain et al., 2007; Aje and Miller, 2009). Geographically, many of developing countries are located in the tropical and sub-tropical regions of the world where $M$. oleifera grows and is cultivated. If validated by medical science, dietary consumption of this plant could be advocated in these and other countries as an inexpensive prophylactic strategy against DM and CVD.

The review covers peer-reviewed studies of the therapeutic potential of $M$. oleifera in these pathologies. It focuses on studies involving experimental animal models and human subjects, in which leaves were used as the medicinal parts of the plant. Leaves were generally administered per os (p.o.) as powders or aqueous or organic extracts thereof, and, for experimental animals, at body weight-adjusted doses. A therapeutic effect was defined as a beneficial change in specific biochemical parameters of disease.
The review includes five sections. The first two sections are concerned with the scientific evidence of M. oleifera efficacy at correcting chronic hyperglycemia or dyslipidemia. They each begin with a brief description of main aspects of glucose or lipid homeostasis and its pathogenic disruption, so that the therapeutic efficacy of the plant could be subsequently evaluated based on current biomedical understanding. The third section attempts to correlate the observed therapeutic effects with the presence in the leaves of physiological properties or chemical constituents experimentally proven to offer such metabolic benefits. The fourth section briefly examines what is known of the possible toxicity of $M$. oleifera leaves. The final section identifies obvious gaps in current knowledge and proposes potential avenues for future investigation.

\section{METHODOLOGY}

Two biomedical literature databases were searched: PubMed and Google Scholar (subsections: Biology, Life Science, Environmental Science, Medicine, Pharmacology, and Veterinary Science). The search was conducted using moringa or drumstick as a keyword within the title of the article. Articles dealing with Moringa varieties other than oleifera were excluded; as were articles in which the word drumstick referred to other subject matters (e.g., medical conditions or transcription factor) than the plant. All the remaining articles, including reviews, were critically read. Peer-reviewed articles presenting results of experimental studies, in animals or humans, on the therapeutic potential of $M$. oleifera leaf extract or powder in chronic hyperglycemia or hyperlipidemia were analyzed for inclusion in this review. The analysis focused on therapy subjects, galenic formulation, mode of administration, dosage, treatment duration, and measurable biochemical outcomes.

\section{THERAPEUTIC POTENTIAL OF M. OLEIFERA IN CHRONIC HYPERGLYCEMIA GLUCOSE HOMEOSTASIS}

Glucose is a major fuel for animal cells. It is supplied to the organism through dietary carbohydrates and, endogenously, through hepatic gluconeogenesis and glycogenolysis. Glucose absorption from the gastrointestinal tract (GIT) into blood is regulated by a variety of neuronal signals and enterohormones (incretins), as well as by meal composition and the intestinal flora. Glucose homeostasis reflects a balance between glucose supply and its utilization. Physiologically, this balance is determined by the level of circulating insulin and tissue responsiveness to it. Insulin is secreted by pancreatic islet $\beta$ cells. It stimulates glucose uptake and utilization by tissues, especially by liver, skeletal muscle, and adipose tissue. It also suppresses gluconeogenesis in hepatocytes, while stimulating lipogenesis and inhibiting lipolysis in adipocytes (Gerich, 2000).

\section{HYPERGLYCEMIA}

An individual is diagnosed as diabetic when his blood glucose level is chronically $\geq 126 \mathrm{mg} / \mathrm{dL}$ after an overnight fast, and $\geq 200 \mathrm{mg} / \mathrm{dL}$ $2 \mathrm{~h}$ after an oral glucose load of $75 \mathrm{~g}$ (oral glucose tolerance test, OGTT; Alberti and Zimmet, 1998). Age, genetics, environment, and lifestyle influence the development of this pathology. The relative importance of these factors and their combinatorial effects are not yet fully understood. Two types of DM are commonly recognized: type $1 \mathrm{DM}$ (T1DM) results from autoimmune destruction 
of pancreatic $\beta$ cells and represents only $5 \%$ of all cases; type- 2 $\mathrm{DM}$ (T2DM) is the most common form of the disease and the primary concern of this review.

In its early stages, T2DM is characterized by chronic hyperglycemia and hyperinsulinemia, due to loss of tissue sensitivity to insulin, and compensatory secretion of the hormone by islet $\beta$ cells. Its progression involves a complex network of interacting cellular and physiological alterations leading to $\beta$ cell failure. Glucotoxicity and lipotoxicity are the most commonly invoked mechanisms for this failure (Robertson et al., 2004).

Glucotoxicity arises from excessive uptake of glucose by islet $\beta$ cells. The excess sugar drives glycation reactions and the mitochondrial electron transport chain, producing macromoleculedamaging reactive oxygen species (ROS), at levels beyond the antioxidation capacity of the cell. The ensuing oxidative stress impairs insulin synthesis and secretion, and initiates a cascade of cellular events that ultimately lead to apoptosis (Kaneto et al., 2007).

Lipotoxicity, on the other hand, results in part from the unresponsiveness of adipocytes to insulin, negating the ability of this hormone to stimulate uptake by these cells of non-esterified fatty acids (NEFA) that result from triglycerides (TG) lipolysis in circulation, and to inhibit lipolysis of endogenous TG to NEFA. Excess plasma NEFA impairs insulin secretion by $\beta$ cells, stimulates gluconeogenesis by liver, and inhibits glucose disposal by skeletal muscle, further exacerbating hyperglycemia (Stumvoll et al., 2005). NEFA accumulation in the bloodstream is further aggravated by obesity, a condition characterized by an expanded adipose mass. Furthermore, adipose tissues, especially the visceral and deep subcutaneous ones, secrete pro-inflammatory cytokines such as interleukin 6 (IL-6) and tumor necrosis factor $\alpha$ (TNF $\alpha)$, which also contribute to tissue insensitivity to insulin.

Impaired TG storage into adipocytes facilitates the formation in the bloodstream of small, cholesterol ester-poor, TG-rich low-density lipoprotein (LDL) particles. Hyperglycemia promotes glycation of these particles, a modification that extends their half-life in circulation. These particles are prone to oxidation and are potent initiators of atherogenesis and its vascular damages (discussed in more detail below). Diabetes-associated neuropathy, retinopathy, and nephropathy are some of the consequences of these damages (Dokken, 2008).

Underlying these complex physiological changes are molecular alterations in the relative levels of expression and posttranslational modifications of a wide variety of gene products, including surface receptors, second messengers and transcriptional factors.

\section{EVIDENCE OF ANTI-HYPERGLYCEMIC PROPERTIES OF M. OLEIFERA}

Moringa oleifera parts have been used in folk medicine for the treatment of diabetes (Dieye et al., 2008). Five studies aimed at verifying these properties using leaves were identified in the scientific literature: two were conducted in experimental animals (Ndong et al., 2007b; Jaiswal et al., 2009) and three in T2DM patients (William et al., 1993; Kumari, 2010; Ghiridhari et al., 2011). They are summarized in Table 1.

\section{Animal studies}

In the study by Ndong et al. (2007b), Goto-Kakizaki (GK) Wistar rats were used as model of DM. GK rats spontaneously develop early glucose intolerance associated with impaired insulin secretion (Bisbis et al., 1993; Abdel-Halim et al., 1995). In an OGTT, overnight fasted Wistar controls or GK male rats were given $2 \mathrm{~g} / \mathrm{kg}$ of body weight (kg-bw) glucose by oral gavage, without or with $200 \mathrm{mg} / \mathrm{kg}$-bw of M. oleifera leaf powder. To determine blood glucose levels, vein blood was collected before gavage and at different times afterward up to $120 \mathrm{~min}$. Areas under the curves (AUC) were derived from the time courses of these levels. In the absence of treatment, fasting plasma glucose levels (FPG) and their postprandial levels $(\mathrm{PPPG})$ at $120 \mathrm{~min}$ were greater $(\sim 1.4 \times$ and $2.2 \times$, respectively) in GK rats than in control rats. Treatment with $M$. oleifera leaf powder resulted in a lower glycemic response in GK and control rats. However, in GK rats, the treatment reduced

Table 1 | Moringa oleifera experimental therapy for chronic hyperglycemia.

\begin{tabular}{|c|c|c|c|c|c|}
\hline \multicolumn{6}{|c|}{ A. ANIMAL MODELS } \\
\hline Species & Inducer & Plant part (extract) & Protocol $^{\mathrm{a}}$ & Corrective outcomes & Reference \\
\hline Rat & STZ & Leaf (water) & 100-300 mg/kg-bw; p.o., single dose; $8 \mathrm{~h}$ & $\begin{array}{l}\downarrow F P G ; \uparrow \text { glucose tolerance } \\
\text { (OGTT) }\end{array}$ & Jaiswal et al. (2009) \\
\hline Rat (GK) & - & Leaf & 200 mg/kg-bw; p.o., single dose; $2 \mathrm{~h}$ & $\begin{array}{l}\uparrow \text { glucose tolerance (OGTT); } \\
\uparrow \text { stomach content }\end{array}$ & Ndong et al. (2007b) \\
\hline \multicolumn{6}{|c|}{ B. HUMAN T2DM PATIENTS (FPG > $9 \mathrm{mmol} / \mathrm{L}$ ) } \\
\hline 6 & 6 & Leaf (meal) & $50 \mathrm{~g} / \mathrm{meal} ;$ p.o. single; 1 or $2 \mathrm{~h}$ & $\downarrow P P P G / F P G$ & William et al. (1993) \\
\hline 46 & 9 & Leaf (tablet) & $8 \mathrm{~g} /$ day; p.o., daily; 40 days & $\downarrow F P G ; \downarrow P P P G$ & Kumari (2010) \\
\hline 30 & 30 & Leaf (tablet) & 2 tablets/day; p.o., daily; 1, 2, 3 months & $\downarrow \mathrm{HbA}_{1 \mathrm{c}} ; \downarrow \mathrm{PPPG}$ & Ghiridhari et al. (2011) \\
\hline
\end{tabular}

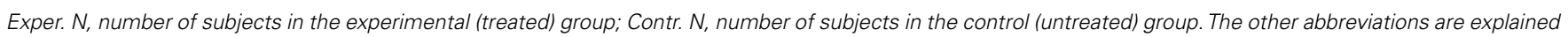
in the text.

${ }^{a}$ The protocol brief description is given in three lines: line 1, dose; line 2, mode of administration and frequency; line 2, duration of treatment before assessment. 
AUC values by $23 \%(P<0.05)$; it did not significantly affect these values in control rats. These observations suggested that $M$. oleifera treatment improves plasma glucose disposal only in the diabetic rats.

In the study by Jaiswal et al. (2009), prediabetes and diabetes were induced in Wistar rats by intraperitoneal (i.p.) injection of $55 \mathrm{mg} / \mathrm{kg}$-bw of streptozotocin (STZ), a cytotoxic drug that selectively destroys islet $\beta$ cells (Like and Rossini, 1976). Based on FPG (mg/dL), STZ-treated rats were classified as sub-diabetic ( $\sim 88 \mathrm{mg} / \mathrm{dL})$, mildly diabetic $(\sim 190 \mathrm{mg} / \mathrm{dL})$, and severely diabetic $(\sim 300 \mathrm{mg} / \mathrm{dL})$. A $M$. oleifera aqueous extract was administered to overnight fasted animals by oral gavage, at 100, 200, or $300 \mathrm{mg} / \mathrm{kg}$-bw. FPG was determined before treatment (baseline) and at various time points post-treatment. An OGTT was conducted $90 \mathrm{~min}$ after the last time point. In normal rats, M. oleifera treatment lowered FPG at all doses in time- and concentrationdependent manners. Six hours after administration, $200 \mathrm{mg} / \mathrm{kg}$-bw of $M$. oleifera extracts lowered FPG by about 26\% $(P<0.05)$, compared to baseline levels or the levels in untreated mice. In an OGTT, at the same dose, a 30\% fall in PPPG was observed after $3 \mathrm{~h}$, in normal, sub-diabetic, and mildly diabetic rats. A 21-day treatment of severely diabetic rats with the $M$. oleifera extract at a daily dose of $300 \mathrm{mg} / \mathrm{kg}$-bw reduced FPG and PPPG by 69 and $51 \%$, respectively, relative to untreated controls. In all the above experiments, the hypoglycemic effect of the plant extract was comparable to that of the anti-diabetic drug Glipizide administered at $2.5 \mathrm{mg} / \mathrm{kg}$-bw.

\section{Human studies}

In a controlled study with untreated T2DM patients, William et al. (1993) examined how M. oleifera addition to a standardized meal, taken after an overnight fast, affected the 1- and 2-h PPPG, relative to the standard meal alone or a 75-g oral glucose load. $M$. oleifera was compared to bitter gourd (Momordica charantia) and curry leaves (Murraya koenigii). Compared to the glucose load, standard meals with or without vegetable supplements induced a significantly lower rise in PPPG (glycemic response) as derived from AUCs. However, when leaf-supplemented meals were compared to standard meals, only the $M$. oleifera leaf-supplemented meal elicited a lower response $(-21 \%, P<0.01)$. Plasma insulin AUCs did not differ significantly between the two meals, suggesting that the hypoglycemic effect of $M$. oleifera leaf supplementation was not due to increased insulin secretion.

Kumari (2010) examined the hypoglycemic effect of $M$. oleifera leaf dietary consumption over a 40-day period in T2DM patients, $30-60$ years of age, not on anti-hyperglycemic medication. The experimental group included 46 subjects, 32 men, and 14 women; the control group of 9 subjects included 4 men and 5 women. Daily meals were comparable among these groups in terms of relative content of food types (e.g., cereals, green leafy vegetables, fruits, etc.) and nutrients (e.g., proteins, fat, fiber, minerals, etc.) as well as calories. The experimental group received a daily dose of $8 \mathrm{~g}$ M. oleifera leaf powder. FPG and PPPG at the end of the protocol (final) were compared to baseline levels. Final values did not differ much from baseline in the control group. They were significantly reduced in the experimental group (FPG: $-28 \%, P<0.01$; PPPG: $-26 \%, P<0.05)$.
More recently, Ghiridhari et al. (2011) studied a group of 60 T2DM patients, age $40-58$ years, BMI $20-25 \mathrm{~kg} / \mathrm{m}^{2}$, on sulfonylurea medication and a standardized calorie-restricted diet. The patients were equally divided into an experimental and a control groups. Patients in the experimental group were prescribed two M. oleifera leaf tablets/day, one after breakfast, the other after dinner for 90 days. M. oleifera leaf powder constituted $98 \%(w / w)$ of the tablet content, but the average weight of tablets was not specified, making the total daily dose unclear. Blood glycated hemoglobin $\left(\mathrm{HbA}_{1 \mathrm{c}}\right)$ was measured before and after the regimen. PPPG was determined before the regimen and every 30 days afterward. In the control group, $\mathrm{HbA}_{1 \mathrm{c}}$ and PPPG progressed downwardly with time, but the change was not significant. In the experimental group, in contrast, relative to the baseline, $\mathrm{HbA}_{1 \mathrm{c}}$ decreased by $0.4 \%$ point (from $7.8 \pm 0.5$ to $7.4 \pm 0.6 ; P<0.01$ ). Compared to the starting levels $(210 \pm 49 \mathrm{mg} / \mathrm{dL})$, PPPG in the experimental group progressively decreased with treatment duration, by $9 \%$ after 30 days, $17 \%$ after 60 days, and $29 \%$ after 90 days $(P<0.01)$, indicating that $M$. oleifera medication can induce with time better glucose tolerance. However, it should be noted that treatment allocation to patients appear to have not been randomized as baseline values for the two parameters were higher in the experimental group than in the control group, $7.8 \pm 0.5$ vs. $7.4 \pm 0.6 \%$ for $\mathrm{HbA}_{1 \mathrm{c}}, 210 \pm 49$ vs. $179 \pm 36 \mathrm{mg} / \mathrm{dL}$ for PPPG.

\section{THERAPEUTIC POTENTIAL OF M. OLEIFERA IN DYSLIPIDEMIA LIPID HOMEOSTASIS}

Lipids constitute a major class of hydrophobic constituents of the body. Their main forms are cholesterol, phospholipids (PL), and triglycerides (TG). Lipids are involved in a variety of biological processes, including membrane formation, intracellular and intercellular signaling, as well as energy storage and production. The body derives its lipids from de novo cellular biosynthesis and from nutrition. Cellular biosynthesis of lipids is regulated at the transcriptional level by sterol-regulated element-binding proteins (SREBPs) 1 and 2. SREBP-1 promotes the biosynthesis fatty acids and TG, SREBP-2 that of cholesterol (Horton, 2002).

Intestinal and plasma lipids are transported by lipoproteins particles. Apolipoproteins (Apo) constitute the protein components of these particles. Lipoproteins vary in density and, depending on their relative contents in TG, cholesterol, and PL, are identified as chylomicrons, very low-density lipoprotein (VLDL), LDL, intermediate density lipoprotein (IDL), and high-density lipoprotein (HDL). Lipids are transported by chylomicrons in the intestinal lymphatic system; and, in the bloodstream, by chylomicron remnants, VLDL, LDL, IDL, and HDL (Abeles et al., 1992; Havel and Kane, 2001).

The liver plays a pivotal role in lipid metabolism. It extracts cholesterol from intestinal chylomicrons and excretes it back into the intestines with bile acids. It biosynthesizes TG and cholesterol and packages them as VLDL, that it secretes into the bloodstream. Through the LDL receptor (LDLR), it clears up plasma LDL as well as IDL from VLDL or HDL catabolism. HDL mediates the reverse transport of cholesterol from extra-hepatic tissues to the liver (Havel and Kane, 2001). Liver LDLR levels and its capacity to clear blood LDL are down-regulated by proprotein convertase 
subtilisin/kexin-type 9 (PCSK9), a plasma protein secreted by this organ (Horton et al., 2009).

\section{DYSLIPIDEMIA}

Dyslipidemia is a disorder characterized by alterations in the levels and composition of plasma lipids. According to Adult Treatment Panel III (2001), plasma levels $\geq 200 \mathrm{mg} / \mathrm{dL}$ for TC, $\geq 130 \mathrm{mg} / \mathrm{dL}$ for LDL-C, $<40 \mathrm{mg} / \mathrm{dL}$ for HDL-C, and $\geq 150 \mathrm{mg} / \mathrm{dL}$ for TG are dyslipidemic. Dyslipidemia may result from inborn defects of lipoprotein production or metabolism; but in most cases, it is secondary to an unhealthy lifestyle (e.g., excessive cigarette smoking or alcohol consumption), other health disorders (e.g., obesity, diabetes, infection, obstructive liver disease), or medication (e.g., $\beta$ blockers, steroids).

Besides hypertension, chronic dyslipidemia is a major cause of atherosclerosis, a vascular disease affecting blood circulation in the coronary, central, and peripheral arteries. The pathology is initiated by irritation of the arterial endothelium by high level of circulating LDL-C, which leads to overexpression of adhesion and chemoattraction molecules (e.g., vascular cell adhesion molecule1 , intercellular adhesion molecule, $\mathrm{P}$ and $\mathrm{E}$ selectins, monocyte chemoattractant protein-1) to injured sites, and the recruitment and capture of circulating monocytes to these sites. These immune cells penetrate into the sub endothelium and differentiate into tissue macrophages, which take up oxidized LDL (oxLDL) via scavenger receptors (e.g., CD36, scavenger receptor-A), becoming the lipid-laden foam cells characteristic of atheromatous plaques. In response to growth factors, resident vascular smooth muscle cells (VSMC) proliferate and form a fibrous cap overlying the plaques. The oxidative process that leads to oxLDL production also contributes to atherogenesis, as this modified lipoprotein and its by-products (oxysterols and oxPL) act as monocyte chemoattractants and VSMC mitogens. Clinical complications of this process include a narrowing of the arterial lumen, plaque rupture, and formation of circulating thrombi. These complications could lead to coronary artery disease (CAD), myocardial infarction, thromboembolic stroke, and peripheral artery disease (Steinberg, 2002; Libby et al., 2011).

Over the years, there has been a vigorous debate over the predictive value of plasma LDL-C level as a marker of CVD risk in humans. An emerging view is that the level of non-HDL lipoproteins, also captured in the TC/HDL-C or HDL-C/non-HDL-C ratio, may constitute a better marker, and its reduction a more cogent measure of the efficacy of anti-dyslipidemia therapies (Sniderman et al., 2010; Manickam et al., 2011).

\section{EVIDENCE OF ANTI-DYSLIPIDEMIC PROPERTY OF M. OLEIFERA}

Five studies were identified in the scientific literature: three were conducted with experimental animals (Ghasi et al., 2000; Chumark et al., 2008; Jain et al., 2010), two with human subjects (Kumari, 2010; Nambiar et al., 2010). They are summarized in Table 2.

\section{Animal studies}

Chumark et al. (2008) examined the therapeutic potential of $M$. oleifera leaves on dyslipidemia induced in rabbits on a highcholesterol (5\%) diet (HCD) for 12 weeks. By the end of the regimen, relative to rabbits on a normal diet, HCD-fed rabbits experienced several-fold $(x)$ increases in the plasma levels of total cholesterol (TC, $55 \times)$, HDL-C $(17 \times)$, LDL-C $(131 \times)$, and TG $(4 \times)$. The diet also caused extensive plaque formation in carotid arteries. When these HCD rabbits were concomitantly fed a $M$. oleifera aqueous leaf extract, at the daily dose of $100 \mathrm{mg} / \mathrm{kg}-\mathrm{bw}$ for the duration of the protocol, these increases were reduced: for TC and lipoprotein-cholesterol by about $50 \%$, for TG by $75 \%$, and for carotic plaque formation by $97 \%$. This protective effect was comparable to that of the anti-cholesterol drug simvastatin, given p.o., at a daily dose of $5 \mathrm{mg} / \mathrm{kg}$-bw. Similar results were also obtained with HCD rabbits fed an aqueous extract of $M$. oleifera fruits (Mehta et al., 2003).

Table 2 | Moringa oleifera experimental therapy for chronic hyperlipidemia.

\begin{tabular}{|c|c|c|c|c|c|}
\hline \multicolumn{6}{|c|}{ A. ANIMAL MODELS } \\
\hline Species & Inducer & Plant part (extract) & Protocol $^{a}$ & Corrective outcomes & Reference \\
\hline Rabbit & HCD & Leaf (water) & 5 mg/kg-bw; p.o., daily; 12 weeks & $\begin{array}{l}\downarrow T C ; \downarrow L D L ; \downarrow H D L ; \downarrow T G ; \\
\downarrow \text { carotid plaque formation }\end{array}$ & Chumark et al. (2008) \\
\hline Rat & HFD & Leaf (water) & 1 g/kg-bw; p.o., daily; 30 days & $\downarrow T C$ & Ghasi et al. (2000) \\
\hline Rat & HFD & Leaf (methanol) & 150-600 mg/kg-bw; p.o., daily; 30 days & $\begin{array}{l}\downarrow T C ; \downarrow L D L ; \uparrow H D L ; \downarrow V L D L ; \\
\downarrow T G ; \uparrow \text { fecal cholesterol; } \\
\downarrow \text { atherogenic index }\end{array}$ & Jain et al. (2010) \\
\hline \multicolumn{6}{|c|}{ B. HUMAN HYPERLIPIDEMICS (TC > $180 \mathrm{mg} / \mathrm{dL}$ or TG $>140 \mathrm{mg} / \mathrm{dL}$ ) } \\
\hline Exper. $\mathbf{N}$ & Contr. N & Plant part (formulation) & Protocol & $\begin{array}{l}\text { Corrective outcomes } \\
\text { (in the experimental group) }\end{array}$ & Reference \\
\hline 17 & 18 & Leaf (tablet) & 4.6 g/day; p.o., daily; 50 days & $\downarrow T C ; \uparrow H D L-C ; \downarrow$ non-HDL-C & Nambiar et al. (2010) \\
\hline 46 & 9 & Leaf (tablet) & 8 g/day; p.o., daily; 40 days & $\downarrow T C ; \downarrow L D L-C ; \downarrow V L D L-C$ & Kumari (2010) \\
\hline
\end{tabular}

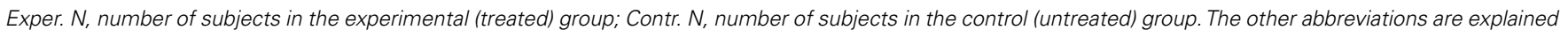
in the text.

${ }^{a}$ The protocol brief description is given in three lines: line 1, dose; line 2, mode of administration and frequency; line 2, duration of treatment before assessment. 
The anti-dyslipidemic effects of $M$. oleifera leaves were also examined in rats fed a high-fat diet (HFD). In one study (Ghasi et al., 2000), Wistar rats were fed, for 30 days, a HFD containing $16 \%(\mathrm{w} / \mathrm{w})$ fat, with or without an aqueous extract of $M$. oleifera leaves at a daily dose of $1 \mathrm{~g} / \mathrm{kg}$-bw. In untreated rats, the diet caused a $30 \%$ increase in plasma TC. In treated rats, the increase was reduced to $14 \%$. In another study (Jain et al., 2010), albino rats were fed, for 30 days, a HFD containing 26\% fat, with or without a methanolic extracts of $M$. oleifera leaves at daily doses of 150,300 , or $600 \mathrm{mg} / \mathrm{kg}$-bw. In untreated rats, the diet increased plasma TC $(2.4 \times)$, LDL-C $(7.7 \times)$, VLDL-C $(1.7 \times)$, and TG $(1.6 \times)$. At the highest dose, M. oleifera treatment reduced these increases to $1.5 \times, 2.2 \times, 1.3 \times$, and $1.3 \times$, respectively $(P<0.01)$. Interestingly, serum HDL-C was unchanged by HFD diet alone; it was increased $2.4 \times$ in rats fed leaf extract-supplemented HFD, significantly reducing the TC/HDL-C ratio.

\section{Human studies}

Nambiar et al. (2010) examined the potential anti-dyslipidemic effect of M. oleifera in 35 hyperlipidemic subjects (TC $>180 \mathrm{mg} / \mathrm{dL}$ or TG $>140 \mathrm{mg} / \mathrm{dL}), 26$ men and 9 women. The control and experimental groups consisted of 18 subjects and 17 subjects, respectively. Anthropometric values (age, height, weight, body mass index, waist/hip ratio) within gender were similar between the two groups, as was their daily nutrient intake. The experimental group consumed a daily total of $4.6 \mathrm{~g}$ of dehydrated $M$. oleifera leaves, as four 550-mg tablets twice daily, for 50 days. Plasma lipid profiles were determined before and after the regimen. Compared to the control group, the experimental group experienced a $1.6 \%$ fall in plasma TC $(P<0.05)$ and a $6.3 \%$ increase of HDL-C, with non-significant trends toward lower LDL-C, VLDL-C, and TG. However, relative to baseline, final non-HDL-C and TC/HDL$\mathrm{C}$ values decreased by 3.7 and $6.6 \%$, respectively $(P<0.001)$, indicating that the treatment induced a lesser atherogenic lipid profile.

In the study of T2DM patients reported by Kumari (2010), the corrective effect of $M$. oleifera dietary leaves on dyslipidemia was also examined. Compared to the control group, the experimental group receiving $8 \mathrm{~g}$ of $M$. oleifera leaf powder daily for 40 days experienced a significant fall in the plasma levels of TC $(-14 \%)$, LDL-C (-29\%), VLDL-C $(-15 \%)$, and TG $(-14 \%$; $P<0.05$ to $<0.01)$. HDL-C increased by $9 \%$ (nonsignificant), but the HDL-C/non-HDL-C ratio increased by $37 \%$ $(P<0.01)$.

\section{PHARMACOLOGY OF M. OLEIFERA LEAVES BROAD-SPECTRUM PHYSIOLOGICAL PROPERTIES}

Because of the chemical complexity of the M. oleifera medicinal formulations used in the studies reviewed above, their apparent therapeutic effects could be due to the combined actions of various bioactive components found in the plant, including trace metal ions, vitamins, alkaloids, carotenoids, polyphenols, fats, carbohydrates, and proteins (Coppin, 2008; Amaglo et al., 2010). Some compounds may collectively affect broad aspects of physiology, such as nutriment absorption and processing, redox state, or immunity.

\section{Anti-nutrient properties}

Moringa oleifera leaves contain phytosterols such as $\beta$-sitosterol (Jain et al., 2010). These compounds can reduce intestinal uptake of dietary cholesterol (Lin et al., 2010). They could partly account for the decrease of plasma cholesterol and the increase of fecal cholesterol observed in rodents treated with M. oleifera leaves (Mehta et al., 2003; Jain et al., 2010). M. oleifera leaf powder also contain about 12\% (w/w) fibers (Joshi and Mehta, 2010). Dietary fibers reduce gastric emptying (Bortolotti et al., 2008). They may partly explain the greater stomach content, the improved OGTT response in treated GK diabetic rats (Ndong et al., 2007b), as well as the progressive improvement of PPPG levels in treated T2DM patients (Ghiridhari et al., 2011).

\section{Antioxidant properties}

The viability and functionality of a cell partly depends on a favorable redox state, i.e., on its ability to prevent excessive oxidation of its macromolecules, including DNA, proteins, and lipids (Ryter et al., 2007; Limon-Pacheco and Gonsebatt, 2009). ROS and free radicals are the major mediators of the oxidative process. Cellular inability to reduce ROS leads to oxidative stress. All cells are variably capable of endogenous self-protection against this stress through the actions of enzymes such as catalase, superoxide dismutase, and glutathione peroxidase, as well as through reducing molecules such as glutathione. Nutritional antioxidants such as vitamins $\mathrm{A}, \mathrm{C}$, and $\mathrm{E}$ provide additional protection from the stress (Limon-Pacheco and Gonsebatt, 2009).

Oxidative stress is widely accepted as a major contributing factor in the pathogenesis of CVD and diabetes (Dhalla et al., 2000; Kaneto et al., 2007; Rodrigo et al., 2011). A recurring explanation for the therapeutic actions of $M$. oleifera medication is the relatively high antioxidant activity of its leaves, flowers, and seeds (Chumark et al., 2008; Sreelatha and Padma, 2009; Verma et al., 2009; Atawodi et al., 2010). Among the major classes of phytochemicals found in the plant, flavonoids appear to carry most of this activity.

\section{Anti-inflammatory properties}

Inflammation with its wide array of cytokines secreted by immune cells is an integral part of the pathophysiology of obesity, hypertension, atherosclerosis, and diabetes (Rana et al., 2007). Extracts from $M$. oleifera leaves have been shown to modulate humoral and cellular immunity in rats and mice (Gupta et al., 2010; Sudha et al., 2010). They have exhibited strong anti-inflammatory properties in rodent models of chemically induced inflammation of the paw (Sulaiman et al., 2008; Mahajan and Mehta, 2009). These properties have been more extensively studied with fruit and seed extracts (Cheenpracha et al., 2010; Mahajan and Mehta, 2010; Muangnoi et al., 2011). They may also contribute to the observed anti-atherogenic and anti-diabetic effects of M. oleifera therapy.

\section{BIOACTIVE PHYTOCHEMICALS}

An informative historical account of research in the phytochemistry of M. oleifera prior to 1995 can be found in Saleem's doctoral thesis available on line (Saleem, 1995). Since then, the research has been expanded and refined, not only on the chemical structures of plant molecules, but also on their nutritional and medicinal 


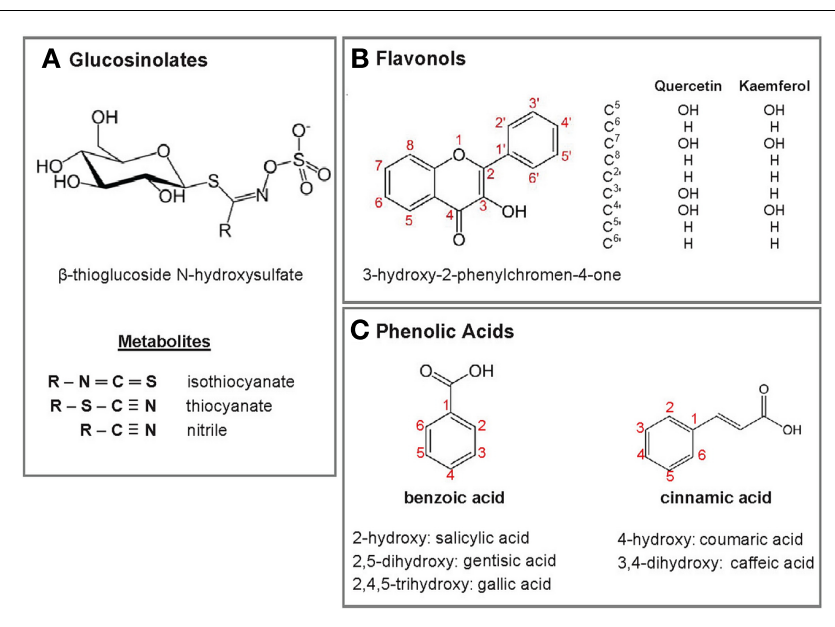

FIGURE 2 | Structural motifs and backbones of major phytochemicals found $\boldsymbol{M}$. oleifera leaves. (A) Glucosinolates and their metabolites.

(B) Flavonol major derivatives. (C) Phenolic acids. Their known derivatives or metabolites are indicated.

properties. Of major medicinal interest are three structural classes of phytochemicals: glucosinolates, flavonoids, and phenolic acids (Saleem, 1995; Bennett et al., 2003; Lako et al., 2007; Manguro and Lemmen, 2007; Coppin, 2008; Amaglo et al., 2010; Kasolo et al., 2010). Their content in M. oleifera leaves varies somewhat with the geographic and climatic conditions under which the plant was grown, as well as with the processing methods for the collected leaves (Bennett et al., 2003; Coppin, 2008; Mukunzi et al., 2011).

Glucosinolates are characterized by $\beta$-thioglucoside $N$ hydroxysulfate motif (Figure 2A). In M. oleifera leaves, most phytochemicals of this class carry a benzyl-glycoside group linked to the single carbon of the motif. The most abundant of them is 4-O-( $\alpha$-L-rhamnopyranosyl-oxy)-benzylglucosinolate, otherwise known as glucomoringin (Amaglo et al., 2010). Enzymatic hydrolysis of the glucosinolate motif of members of this class leads to the formation of corresponding isothiocyanates, thiocyanates, or nitriles. Several of these by-products have been shown to possess antihypertensive properties (Faizi et al., 1992, 1994, 1998).

Flavonoids and phenolic acids are collectively referred to phenolic compounds. The structural skeleton of flavonoids is made of two aromatic rings joined by a three-carbon link; that of the sub-class of flavonols is 3-hydroxy-2-phenylchromen-4one (Figure 2B). Quercetin and kaempferol, in their as $3^{\prime}-O$ glycoside forms, are the predominant flavonols in $M$. oleifera leaves. The sugar moieties include, among others, rhamnoglycosyl (rutinosides), glucosyl (glucosides), $6^{\prime}$ malonyglucosyl, and 2'-galloylrutinoside groups (Bennett et al., 2003; Manguro and Lemmen, 2007; Amaglo et al., 2010). Biologically, flavonoids are best known for their antioxidant properties, but their metabolic pathways of activity remain to be fully elucidated (Rice-Evans, 2001). Phenolic acids have benzoic acid and cinnamic acid as backbones, with one or several hydroxyl groups (Figure 2C). Chlorogenic acid, which is an ester of dihydrocinnamic acid (caffeic acid) and quinic acid, is a major phenolic acid in M. oleifera leaves (Bennett et al., 2003; Amaglo et al., 2010).
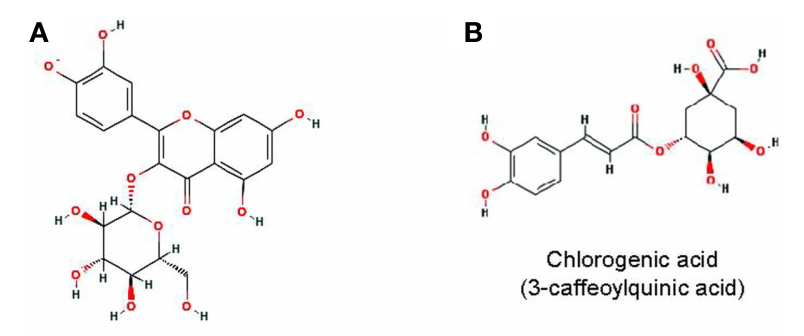

Quercetin-3-O-beta-D-glucoside (isoquercitrin, isotrifolin, ) c
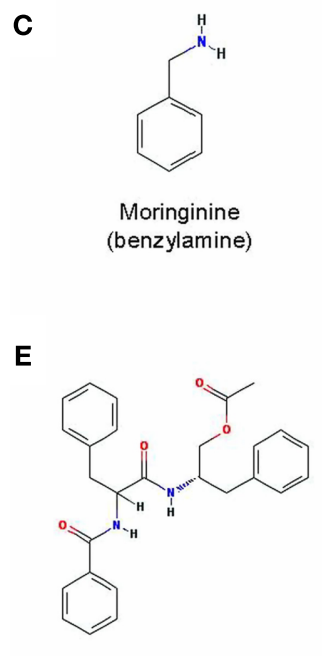

Moringinine (benzylamine)

Aurantiamide acetate
D

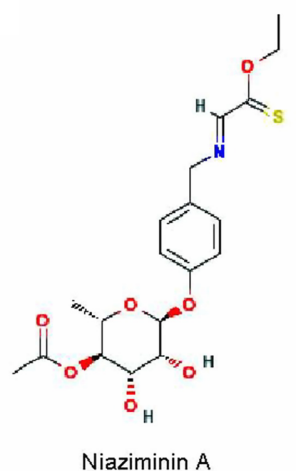

FIGURE 3 | Some bioactive phytochemicals found $\boldsymbol{M}$. oleifera leaves. Their structures were obtained from the online in the PubChem database at www.pubmed.ncbi.nlm.nih.org/.

Four of the best-characterized phytochemicals for their therapeutic efficacy in hyperglycemia, dyslipidemia, or related physiological conditions are shown in Figure 3.

\section{Quercetin}

The flavonol quercetin is found at concentrations as high as $100 \mathrm{mg} / 100 \mathrm{~g}$ of dried M. oleifera leaves (Lako et al., 2007), predominantly as quercetin-3-O- $\beta$-D-glucoside also known as isoquercitrin or isotrifolin (Bennett et al., 2003; Atawodi et al., 2010; Figure 3A). Quercetin is a potent antioxidant (Zhang et al., 2011) with multiple therapeutic properties (Bischoff, 2008). It can reduce hyperlipidemia and atherosclerosis in HCD or HFD rabbits (Juzwiak et al., 2005; Kamada et al., 2005). It has shown antidyslipidemic, hypotensive, and anti-diabetic effects in the obese Zucker rat model of metabolic syndrome (Rivera et al., 2008). It can protect insulin-producing pancreatic $\beta$ cells from STZinduced oxidative stress and apoptosis in rats (Coskun et al., 2005). Its hypotensive effect has been confirmed in a randomized, doubleblind placebo-controlled, human study (Edwards et al., 2007).

\section{Chlorogenic acid}

Chlorogenic acid (Figure 3B) can beneficially affect glucose metabolism. It has been shown to inhibit glucose-6-phosphate 
translocase in rat liver, reducing hepatic gluconeogenesis and glycogenolysis (Hemmerle et al., 1997; Karthikesan et al., 2010a). It was found to lower PPBG in obese Zucker rats (Rodriguez de Sotillo and Hadley, 2002). In OGTT experiments performed on rats or humans, it reduced the glycemic response in both species (van Dijk et al., 2009; Tunnicliffe et al., 2011); in rodents, it also reduced the glucose AUC (Tunnicliffe et al., 2011). Its anti-dyslipidemic properties are more evident as its dietary supplementation has been shown to significantly reduce plasma TC and TG in obese Zucker rats or HFD mice (Rodriguez de Sotillo and Hadley, 2002; Cho et al., 2010) and to reverse STZ-induced dyslipidemia in diabetic rats (Karthikesan et al., 2010b).

\section{Moringinine}

The alkaloid moringinine was initially purified from M. oleifera root bark (Ghosh et al., 1935) and later chemically identified as benzylamine (Chakravarti, 1955; Figure 3C). It is also present in leaves. This substance was suspected to mediate the hypoglycemic effect of the plant. An early study showed that Wistar rats provided with drinking water containing $2.9 \mathrm{~g} / \mathrm{L}$ of benzylamine for 7 weeks exhibited a reduced hyperglycemic response in an intraperitoneal glucose tolerance test (IPGTT), suggesting improved glucose tolerance (Bour et al., 2005). More recently, the effect was further explored using HFD-fed, insulin-resistant C57BL/6 mice taking an estimated daily dose $386 \mathrm{mg} / \mathrm{kg}$-bw in drinking water for 17 weeks. Compared to untreated controls, these mice gained less weight, had reduced FPG and plasma TC, and were more glucose tolerant (Iffiu-Soltesz et al., 2010).

\section{Niaziminin}

Niaziminin (Figure 3D) is a mustard oil glycoside initially isolated (along with other glycosides such as niazinin and niazimicin) from ethanolic extracts of M. oleifera leaves, based on their hypotensive properties on Wistar rats. At $1 \mathrm{mg}$ and $3 \mathrm{mg} / \mathrm{kg}$-bw, these compounds caused a $16-22$ and a $40-65 \%$ fall of mean arterial blood pressure (MABP), respectively (Faizi et al., 1992). Other active isothiocyanate glycosides and thiocarbamates were isolated from the plant using the same bioassay (Faizi et al., 1994, 1998; Saleem, 1995).

\section{Aurantiamide acetate}

This compound was isolated from M. oleifera roots and structurally identified as $N$-benzoylphenylalanyl phenylalinol acetate (Figure 3E). At $25 \mu \mathrm{M}$, this unusual dipeptide derivative inhibited by nearly $90 \%$ the secretion TNF $\alpha$ and IL-2 from lipopolysaccharide-stimulated peripheral blood lymphocytes in culture. It had no effect on IL-6 secretion (Sashidhara et al., 2009). This inhibitory activity may contribute to the anti-inflammatory properties of the plant.

\section{TOXICOLOGY OF M. OLEIFERA THERAPY LEAVES}

In the studies reviewed in this report, no acute or sub-acute toxicity was reported following treatment with $M$. oleifera leaves at the dosage used. The toxicology of this phytotherapy was specifically addressed in two studies. Using rats, Adedapo et al. (2009) examined the safety of an aqueous extract of $M$. oleifera taken orally at $400,800,1600$, and $2000 \mathrm{mg} / \mathrm{kg}$-bw ( $n=6$ rats $/$ dose). The treatment was either acute (single dose followed by a 48 -h observation period), or sub-acute (daily doses, except the highest, for 21 days followed by hematological profiling). Acute treatment caused no death at 400 or $800 \mathrm{mg} / \mathrm{kg}$-bw; it caused $1 / 6$ and $2 / 6$ deaths at 1600 and $2000 \mathrm{mg} / \mathrm{kg}$-bw, respectively. At these high doses, surviving rats exhibited transient dullness for up to $5 \mathrm{~h}$. Sub-acute treatment with $400 \mathrm{mg} / \mathrm{kg}$-bw caused a modest (10\%), but significant $(P<0.05)$ increase in packed cell volume (PCV) and white-blood cell (WBC) count; with $800 \mathrm{mg} / \mathrm{kg}$-bw, it lowered the PCV, but increased the WBC; with $1600 \mathrm{mg} / \mathrm{kg}$-bw, it lowered both parameters. The WBC changes affected lymphocytes, neutrophils, and monocytes, but not eosinophils. Blood levels of aspartate aminotransferase (AST), alanine aminotransferase (ALT), and alkaline phosphatase (ALP) were also examined as surrogate indicators of hepatic function. The results were inconsistent: treatment with 400 and $1600 \mathrm{mg} / \mathrm{kg}$-bw increased AST and ALT levels by $40-50 \%$; with $800 \mathrm{mg} / \mathrm{kg}$-bw, it lowered it by about 50\%. A 70\% increase in ALP levels was observed only after treatment with $1600 \mathrm{mg} / \mathrm{kg}$-bw. Histological examination of tissue sections stained with hematoxylin and eosin revealed no alteration in testis or kidney; a diffuse tissue degeneration was noted in liver. Interestingly, a dose-dependent reduction of body weight gain was noted at the term of the subacute treatment with $M$. oleifera extract: whereas untreated rats gained $53 \%$ more weight, those treated with $400,800,1600 \mathrm{mg} / \mathrm{kg}$ bw of extract gained only 37,27 , and $18 \%$, more, respectively. It is unclear whether this effect is symptomatic of an underlying pathology or indicative of a potential anti-obesity property of the plant. Considering the alterations induced by the sub-acute treatment to be mild, the investigators concluded that nutritional and therapeutic consumption of $M$. oleifera leaves at doses below $2 \mathrm{~g} / \mathrm{kg}$-bw is safe.

Other investigators have examined the effects of hexane extracts of M. oleifera leaves on the reproductive organs of male mice after an oral gavage at 17,170 , and $1700 \mathrm{mg} / \mathrm{kg}$-bw/day for 21 days. They observed a dose-dependent significant increase in testis and epididymis weights, in seminiferous tubule diameter and in epididymal epithelium thickness, but no change in the plasma levels of gonadotropins. They concluded that these changes reflected enhanced spermatogenesis (Cajuday and Pocsidio, 2010).

Several studies using experimental rodent models have shown that $M$. oleifera leaf extracts can protect the liver from chemically induced damage (Pari and Kumar, 2002; Ndong et al., 2007a; Fakurazi et al., 2008; Buraimoh, 2011).

\section{CONCLUSION AND PERSPECTIVES}

Collectively, the studies described in this review provide compelling, albeit very preliminary, experimental evidence of a therapeutic potential of $M$. oleifera leaves in chronic hyperglycemia and dyslipidemia. No report contradicting this evidence was found in the scientific literature. A common weakness of all the human studies reviewed herein was the fact that none was randomized and double-blind, raising the possibilities of bias in the allocation of patients to control and experimental groups.

In spite of converging results, a comparative analysis of these studies is made difficult by variations in agro-climatic conditions of plant growth and harvesting, in leaf processing methods, in final galenic formulations, and in therapeutic protocols. The phytochemical composition of $M$. oleifera parts have been shown to 
vary significantly among regions and seasons (Iqbal and Bhanger, 2006; Juliani et al., 2009). Leaf extraction solvents determine the nature and the relative concentrations of bioactive or medicinal ingredients found in final galenic formulations (Siddhuraju and Becker, 2003).

Evaluation of the phytotherapy was often restricted to a narrow set of parameters of disease. For examples, most studies of the anti-diabetic effects were limited to measures of FPG and PPPG levels. Fasting and post-OGTT insulin levels were almost never examined to verify whether the treatment improved the ability of the endocrine pancreas to produce and secrete this hormone in response to elevated blood glucose. Insulin clamp studies would have clarified whether the treatment increased tissue sensitivity to the hormone. Since the medication was administered p.o., measures of plasma levels of incretins and other enterohormones would have given insights on how GIT physiology is affected by the treatment.

In the same vein, it is unclear whether the hypocholesterolemic effect of the therapy was associated with repressed de novo cholesterol biosynthesis (a statin-like effect), increased hepatic cholesterol clearance (statin-like or anti-PCSK9-like effects) or increased intestinal excretion. It might be interesting to find the physiological basis of the cardioprotective increase of the TC/non-HDL-C ratio following treatment. A more extensive analysis on circulating biochemical markers of inflammation would be justified, as the balance of pro and anti-inflammatory cytokines could influence the course of both diabetes and atherosclerosis.

Besides a rationalized investigation of the therapeutic effect of $M$. oleifera leaves, it is possible to conduct an unbiased search for the affected physiological pathways. This could be achieved by globally comparing tissues or fluids of untreated and treated animals or humans, using the powerful techniques of systems biology, the so-called "omics" (transcriptomics, proteomics, and

\section{REFERENCES}

Abdel-Halim, S. M., Ostenson, C. G., Andersson, A., Jansson, L., and Efendic, S. (1995). A defective stimulussecretion coupling rather than glucotoxicity mediates the impaired insulin secretion in the mildly diabetic F1 hybrids of GK-Wistar rats. Diabetes 44, 1280-1284.

Abeles, R. H., Frey, P. A., and Jencks, W. P. (1992). "Complex lipids," in Biochemistry (Boston: Jones and Bartlett Publishers), 739-761.

Adedapo, A. A., Mogbojuri, O. M., and Emikpe, B. O. (2009). Safety evaluations of the aqueous extract of the leaves of Moringa oleifera in rats. $J$. Med. Plant 3, 586-591.

Adult Treatment Panel III. (2001). Executive summary of the third report of The National Cholesterol Education Program (NCEP) expert panel on detection, evaluation, and treatment of high blood cholesterol in adults (Adult Treatment Panel III). JAMA 285, 2486-2497.

metabolomics), combined with the equally powerful algorithms of modern bioinformatics (Zhang et al., 2010).

Further exploration of the potentials and the eventual use of M. oleifera therapy in humans will require that reference standards be set for its cultivation, the collection of its parts, as well as for their final conditioning under good agricultural and collection practices (GACP). Such guidelines, specifically directed toward medicinal plants have been defined by the WHO (2003). Furthermore, when the pharmacological basis of the therapeutic effects on a particular pathology is rationally well circumscribed, standardized assays should be required to evaluate all galenic lots for the relevant properties. For example, on the basis of current knowledge, it would indicated that the content in fibers, phytosterols as well in antioxidant and anti-inflammatory activities be evaluated and documented in M. oleifera galenic formulations destined to the treatment of atherosclerosis or diabetes. The shelf life of these properties under specified storage conditions should also be established.

In conclusion, based on the available experimental evidence, $M$. oleifera leaf powder holds some therapeutic potential for chronic hyperglycemia and hyperlipidemia. However, before it is advocated in any formulation for the treatment of these metabolic disorders in humans, state-of-the art clinical studies must be conducted to establish the consistency of its medicinal efficacy and the safest modalities of its administration.

\section{ACKNOWLEDGMENTS}

The author thanks Drs. Ajoy Basak, Michel Chrétien, Hugues Loemba, and Teik Chye Ooi for their critical review of the manuscript. He is also grateful to Ms. Denise Joanisse for her invaluable assistance in bibliographical search. The work was supported by grants from the Canadian Institute of Health Research and from the Strauss Foundation.

M. (2005). Mineral composition of Moringa oleifera leaves and pods from dfferent regions of Punjab, Pakistan. Asian J. Plant Sci. 4, 417-421.

Atawodi, S. E., Atawodi, J. C., Idakwo, G. A., Pfundstein, B., Haubner, R., Wurtele, G., Bartsch, H., and Owen, R. W. (2010). Evaluation of the polyphenol content and antioxidant properties of methanol extracts of the leaves, stem, and root barks of Moringa oleifera Lam. J. Med. Food 13, 710-716.

Bennett, R. N., Mellon, F. A., Foidl, N., Pratt, J. H., Dupont, M. S., Perkins, L., and Kroon, P. A. (2003). Profiling glucosinolates and phenolics in vegetative and reproductive tissues of the multi-purpose trees Moringa oleifera L. (horseradish tree) and Moringa stenopetala L. J. Agric. Food Chem. 51, 3546-3553.

Bisbis, S., Bailbe, D., Tormo, M. A. Picarel-Blanchot, F., Derouet, M., Simon, J., and Portha, B. (1993). Insulin resistance in the GK rat: decreased receptor number but normal kinase activity in liver. Am. J. Physiol. 265, E807-E813.

Bischoff, S. C. (2008). Quercetin: potentials in the prevention and therapy of disease. Curr. Opin. Clin. Nutr. Metab. Care 11, 733-740.

Bortolotti, M., Levorato, M., Lugli, A., and Mazzero, G. (2008). Effect of a balanced mixture of dietary fibers on gastric emptying, intestinal transit and body weight. Ann. Nutr. Metab. 52, 221-226.

Bour, S., Visentin, V., Prevot, D., Daviaud, D., Saulnier-Blache, J. S., Guigne, C., Valet, P., and Carpene, C. (2005). Effects of oral administration of benzylamine on glucose tolerance and lipid metabolism in rats. J. Physiol. Biochem. 61, 371-379.

Buraimoh, A. A. (2011). Hepatoprotective effect of ethanolic leave extract of Moringa oleifera on the histology of paracetamol induced liver damage in Wistar rats. Int. J. Anim. Vet. Adv. 3, 10-13. 
Cajuday, L. A., and Pocsidio, G. L. (2010). Effects of Moringa oleifera Lam. (Moringaceae) on the reproduction of male mice (Mus musculus). J. Med. Plant Res. 4, 1115-1121.

Chakravarti, R. N. (1955). Chemical identity of moringine. Bull. Calcutta Sch. Trop. Med. 3, 162-163.

Cheenpracha, S., Park, E. J., Yoshida, W. Y., Barit, C., Wall, M., Pezzuto, J. M., and Chang, L. C. (2010). Potential anti-inflammatory phenolic glycosides from the medicinal plant Moringa oleifera fruits. Bioorg. Med. Chem. 18, 6598-6602.

Cho, A. S., Jeon, S. M., Kim, M. J., Yeo, J., Seo, K. I., Choi, M. S., and Lee, M. K. (2010). Chlorogenic acid exhibits anti-obesity property and improves lipid metabolism in highfat diet-induced-obese mice. Food Chem. Toxicol. 48, 937-943.

Chumark, P., Khunawat, P., Sanvarinda, Y., Phornchirasilp, S., Morales, N. P., Phivthong-Ngam, L., Ratanachamnong, P., Srisawat, S., and Pongrapeeporn, K. U. (2008). The in vitro and ex vivo antioxidant properties, hypolipidaemic and antiatherosclerotic activities of water extract of Moringa oleifera Lam. leaves. J. Ethnopharmacol. 116, 439-446.

Coppin, J. (2008). A Study of the Nutritional and Medicinal Values of Moringa oleifera Leaves from sub-Saharan Africa: Ghana, Rwanda, Senegal and Zambia. M.Sc. thesis, Rutgers University-Graduate SchoolNew Brunswick, New Brunswick.

Coskun, O., Kanter, M., Korkmaz, A., and Oter, S. (2005). Quercetin, a flavonoid antioxidant, prevents and protects streptozotocin-induced oxidative stress and beta-cell damage in rat pancreas. Pharmacol. Res. 51, 117-123.

Dhalla, N. S., Temsah, R. M., and Netticadan, T. (2000). Role of oxidative stress in cardiovascular diseases. $J$. Hypertens. 18, 655-673.

Dieye, A. M., Sarr, A., Diop, S. N., Ndiaye, M., Sy, G. Y., Diarra, M., Rajraji Gaffary, I., Ndiaye Sy, A., and Faye, B. (2008). Medicinal plants and the treatment of diabetes in Senegal: survey with patients. Fundam. Clin. Pharmacol. 22, 211-216.

Dokken, B. B. (2008). The pathophysiology of cardiovascular disease and diabetes: beyond blood pressure and lipids. Diabetes Spectr. 21, 160-165.

Edwards, R. L., Lyon, T., Litwin, S. E., Rabovsky, A., Symons, J. D., and Jalili, T. (2007). Quercetin reduces blood pressure in hypertensive subjects. J. Nutr. 137, 2405-2411.
Faizi, S., Siddiqui, B. S., Saleem, R., Aftab, K., Shaheen, F., and Gilani, A. H. (1998). Hypotensive constituents from the pods of Moringa oleifera. Planta Med. 64, 225-228.

Faizi, S., Siddiqui, B. S., Saleem, R., Siddiqui, S., and Aftab, K. (1992). Isolation and structure elucidation of novel hypotensive agents, niazinin $A$, niazinin $B$, niazimicin and niaziminin $\mathrm{A}+\mathrm{B}$ from Moringa oleifera: the first naturally occurring thiocarbamates. J. Chem. Soc. 1 , 3237-3241.

Faizi, S., Siddiqui, B. S., Saleem, R., Siddiqui, S., Aftab, K., and Gilani, A. H. (1994). Isolation and structure elucidation of new nitrile and mustard oil glycosides from Moringa oleifera and their effect on blood pressure. J. Nat. Prod. 57, 1256-1261.

Fakurazi, S., Hairuszah, I., and Nanthini, U. (2008). Moringa oleifera Lam prevents acetaminophen induced liver injury through restoration of glutathione level. Food Chem. Toxicol. 46, 2611-2615.

Gerich, J. E. (2000). Physiology of glucose homeostasis. Diabetes Obes. Metab. 2, 345-350.

Ghasi, S., Nwobodo, E., and Ofili, J. O. (2000). Hypocholesterolemic effects of crude extract of leaf of Moringa oleifera Lam in high-fat diet fed Wistar rats. J. Ethnopharmacol. 69, 21-25.

Ghiridhari, V. V. A., Malhati, D., and Geetha, K. (2011). Anti-diabetic properties of drumstick (Moringa oleifera) leaf tablets. Int. J. Health Nutr. 2, 1-5.

Ghosh, S., Chopra, N. R., and Dutt, A. (1935). Chemical examination of bark of Moringa pterygosperma. Indian J. Med. Res. 22, 789.

Gowrishankar, R., Kumar, M., Menon, V., Divi, S. M., Saravanan, M., Magudapathy, P., Panigrahi, B. K., Nair, K. G., and Venkataramaniah, K. (2010). Trace element studies on Tinospora cordifolia (Menispermaceae), Ocimum sanctum (Lamiaceae), Moringa oleifera (Moringaceae), and Phyllanthus niruri (Euphorbiaceae) using PIXE. Biol. Trace Elem. Res. 133, 357-363.

Gupta, A., Gautam, M. K., Singh, R. K., Kumar, M. V., Rao Ch, V., Goel, R. K., and Anupurba, S. (2010). Immunomodulatory effect of Moringa oleifera Lam. extract on cyclophosphamide induced toxicity in mice. Indian J. Exp. Biol. 48, 1157-1160.

Havel, R. J., and Kane, J. P. (2001). "Tructure and metabolism of plasma lipoproteins," in The Metabolic and
Molecular Basis of Inherited Disease, eds C. R. Scriver, A. L. Beaudet, W. S. Sly, M. D. Valle, B. Childs, K. W. Kinzler, and B. Vogelstein (New York: McGraw-Hill), 2705-2716.

Hemmerle, H., Burger, H. J., Below, P., Schubert, G., Rippel, R., Schindler, P. W., Paulus, E., and Herling, A. W. (1997). Chlorogenic acid and synthetic chlorogenic acid derivatives: novel inhibitors of hepatic glucose-6-phosphate translocase. $J$. Med. Chem. 40, 137-145.

Horton, J. D. (2002). Sterol regulatory element-binding proteins: transcriptional activators of lipid synthesis. Biochem. Soc. Trans. 30, 1091-1095.

Horton, J. D., Cohen, J. C., and Hobbs, H. H. (2009). PCSK9: a convertase that coordinates LDL catabolism. $J$. Lipid Res. 50(Suppl.), S172-S177.

Hossain, P., Kawar, B., and El Nahas, M. (2007). Obesity and diabetes in the developing world - a growing challenge. N. Engl. J. Med. 356, 213-215.

Iffiu-Soltesz, Z., Wanecq, E., Lomba, A., Portillo, M. P., Pellati, F., Szoko, E., Bour, S., Woodley, J., Milagro, F. I., Alfredo Martinez, J., Valet, P., and Carpene, C. (2010). Chronic benzylamine administration in the drinking water improves glucose tolerance, reduces body weight gain and circulating cholesterol in highfat diet-fed mice. Pharmacol. Res. 61 , 355-363.

Iqbal, S., and Bhanger, M. I. (2006). Effect of season and production location on antioxidant activity of Moringa oleifera leaves grown in Pakistan. J. Food Compost. Anal. 19, 544-551.

Jain, P. J., Patil, S. D., Haswani, N. G., Girase, M. V., and Surana, S. J. (2010). Hypolipidemic activity of Moringa oleifera Lam., Moringaceae, on high fat died-induced hyperlipidemia in albino rats. Braz. J. Pharmacogn. 20, 969-973.

Jaiswal, D., Kumar Rai, P., Kumar, A., Mehta, S., and Watal, G. (2009). Effect of Moringa oleifera Lam. leaves aqueous extract therapy on hyperglycemic rats. J. Ethnopharmacol. 123, 392-396.

Joshi, P., and Mehta, D. (2010). Effect of dehydration on the nutritive value of drumstick leaves. Metabolomics 1 , 5-9.

Juliani, H. R., Yudy Fonseca, Y., Dan Acquaye, A., Halimu Malumo, H. Malainy, D., and Simon, J. E. (2009). "Nutritional assessment of Moringa (Moringa spp.) from Ghana, Senegal and Zambia," in African Natural Plant Products: New Discoveries and Challenges in Chemistry and Quality, eds H. R. Juliani, J. E. Simon, and C. T. Ho (Washington: American Chemical Society), 469-484.

Juzwiak, S., Wojcicki, J., Mokrzycki, K., Marchlewicz, M., Bialecka, M., Wenda-Rozewicka, L., GawronskaSzklarz, B., and Drozdzik, M. (2005). Effect of quercetin on experimental hyperlipidemia and atherosclerosis in rabbits. Pharmacol. Rep. 57, 604-609.

Kamada, C., da Silva, E. L., OhnishiKameyama, M., Moon, J. H., and Terao, J. (2005). Attenuation of lipid peroxidation and hyperlipidemia by quercetin glucoside in the aorta of high cholesterol-fed rabbit. Free Radic. Res. 39, 185-194.

Kaneto, H., Katakami, N., Kawamori, D., Miyatsuka, T., Sakamoto, K., Matsuoka, T. A., Matsuhisa, M., and Yamasaki, Y. (2007). Involvement of oxidative stress in the pathogenesis of diabetes. Antioxid. Redox Signal. 9, 355-366

Karthikesan, K., Pari, L., and Menon, V. P. (2010a). Antihyperlipidemic effect of chlorogenic acid and tetrahydrocurcumin in rats subjected to diabetogenic agents. Chem. Biol. Interact. 188, 643-650.

Karthikesan, K., Pari, L., and Menon, V. P. (2010b). Combined treatment of tetrahydrocurcumin and chlorogenic acid exerts potential antihyperglycemic effect on streptozotocin-nicotinamideinduced diabetic rats. Gen. Physiol. Biophys. 29, 23-30.

Kasolo, J. N., Bimenya, G. S., Ojok, L., Ochleng, J., and Ogwal-Okeng, J. W. (2010). Phyochemicals and uses of Moringa oleifera leaves in Ugandan rural communities. J. Med. Plant Res. 4,753-757.

Kumar, P. S., Mishra, D., Ghosh, G., and Panda, G. S. (2010). Medicinal uses and pharmacological properties of Moringa oleifera. Int. J. Phytomed. 2, 210-216.

Kumari, D. J. (2010). Hypoglycemic effect of Moringa oleifera and Azadirachta indica in type-2 diabetes. Bioscan 5, 211-214.

Lako, J., Trenerry, V. C., Wahlqvist, M., Wattanapenpaiboon, N., Sotheeswaran, S., and Premier, R. (2007). Phytochemical flavonols, carotenoids and the antioxidant properties of a wide selection of Fijian fruit, vegetables and other readily available foods. Food Chem. 101, 1727-1741. 
Libby, P., Ridker, P. M., and Hansson, G. K. (2011). Progress and challenges in translating the biology of atherosclerosis. Nature 473, 317-325.

Like, A. A., and Rossini, A. A. (1976). Streptozotocin-induced pancreatic insulitis: new model of diabetes mellitus. Science 193, 415-417.

Limon-Pacheco, J., and Gonsebatt, M. E. (2009). The role of antioxidants and antioxidant-related enzymes in protective responses to environmentally induced oxidative stress. Mutat. Res. 674, 137-147.

Lin, X., Racette, S. B., Lefevre, M., Spearie, C. A., Most, M., Ma, L., and Ostlund, R. E. Jr. (2010). The effects of phytosterols present in natural food matrices on cholesterol metabolism and LDL-cholesterol: a controlled feeding trial. Eur. J. Clin. Nutr. 64, 1481-1487.

Mahajan, S., and Mehta, A. (2009). Curative effect of hydroalcoholic extract of leaves of Moringa oleifera lam. against adjuvant induced established arthritis in rats. Niger. J. Nat. Prod. Med. 13, 13-22.

Mahajan, S. G., and Mehta, A. A. (2010). Immunosuppressive activity of ethanolic extract of seeds of Moringa oleifera Lam. in experimental immune inflammation. J. Ethnopharmacol. 130, 183-186.

Manguro, L. O., and Lemmen, P. (2007). Phenolics of Moringa oleifera leaves. Nat. Prod. Res. 21, 56-68.

Manickam, P., Rathod, A., Panaich, S., Hari, P., Veeranna, V., Badheka, A., Jacob, S., and Afonso, L. (2011). Comparative prognostic utility of conventional and novel lipid parameters for cardiovascular disease risk prediction: do novel lipid parameters offer an advantage? J. Clin. Lipidol. 5, 82-90.

Mehta, K., Balaraman, R., Amin, A. H., Bafna, P. A., and Gulati, O. D. (2003). Effect of fruits of Moringa oleifera on the lipid profile of normal and hypercholesterolaemic rabbits. J. Ethnopharmacol. 86, 191-195.

Monera, T. G., and Maponga, C. C. (2010). Moringa oleifera supplementation by patients on antiretroviral therapy. J. Int. AIDS Soc. 13, 188.

Muangnoi, C., Chingsuwanrote, P., Praengamthanachoti, P., Svasti, S., and Tuntipopipat, S. (2011). Moringa oleifera pod inhibits inflammatory mediator production by lipopolysaccharide-stimulated RAW 264.7 murine macrophage cell lines. Inflammation. doi: 10.1007/s10753-011-9334-4. [Epub ahead of print].
Mukunzi, D., Nsor-Atindana, J., Xiaoming, Z., Gahungu, A., Karangwa, E., Mukamurezi, G., Al-Domi, H., Princewill-Ogbonna, I. L., Ogbonna, P. C., and Arief, N. J. (2011). Comparison of volatile profile of Moringa oleifera leaves from Rwanda and China using HS-SPME. Pakistan J. Nutr. 10, 602-608.

Nambiar, V. S., Guin, P., Parnami, S., and Daniel, M. (2010). Impact of antioxidants from drumstick leaves on the lipid profile of hyperlipidemics. J. Herb. Med. Toxicol. 4, 165-172.

Ndong, M., Uehara, M., Katsumata, S., Sato, S., and Suzuki, K. (2007a). Preventive effects of Moringa oleifera (Lam) on hyperlipidemia and hepatocyte ultrastructural changes in iron deficient rats. Biosci. Biotechnol. Biochem. 71, 1826-1833.

Ndong, M., Uehara, M., Katsumata, S., and Suzuki, K. (2007b). Effects of oral administration of Moringa oleifera Lam on glucose tolerance in Goto-Kakizaki and Wistar rats. J. Clin. Biochem. Nutr. 40, 229-233.

Olson, M. E. (2002). Combining data from DNA sequences and morphology for a phylogeny of Moringaceae (Brassicales). Syst. Bot. 27, 55-73.

Pari, L., and Kumar, N. A. (2002). Hepatoprotective activity of Moringa oleifera on antitubercular drug-induced liver damage in rats. J. Med. Food 5, 171-177.

Ramachandran, C., Peter, K. V., and Gopalakrishnan, P. K. (1980). Drumstick (Moringa oleifera): a multipurpose Indian vegetable. Econ. Bot. 34, 276-283.

Rana, J. S., Nieuwdorp, M., Jukema, J. W., and Kastelein, J. J. (2007). Cardiovascular metabolic syndrome an interplay of, obesity, inflammation, diabetes and coronary heart disease. Diabetes Obes. Metab. 9, 218-232.

Rice-Evans, C. (2001). Flavonoid antioxidants. Curr. Med. Chem. 8, 797-807.

Rivera, L., Moron, R., Sanchez, M., Zarzuelo, A., and Galisteo, M. (2008). Quercetin ameliorates metabolic syndrome and improves the inflammatory status in obese Zucker rats. Obesity (Silver Spring) 16, 2081-2087.

Robertson, R. P., Harmon, J., Tran, P. O., and Poitout, V. (2004). Betacell glucose toxicity, lipotoxicity, and chronic oxidative stress in type 2 diabetes. Diabetes 53(Suppl. 1), S119S124.

Rodrigo, R., Gonzalez, J., and Paoletto, F. (2011). The role of oxidative stress in the pathophysiology of hypertension. Hypertens. Res. 34, 431-440.
Rodriguez de Sotillo, D. V., and Hadley, M. (2002). Chlorogenic acid modifies plasma and liver concentrations of: cholesterol, triacylglycerol, and minerals in $(\mathrm{fa} / \mathrm{fa})$ Zucker rats. J. Nutr. Biochem. 13, 717-726.

Ryter, S. W., Kim, H. P., Hoetzel, A., Park, J. W., Nakahira, K., Wang, X., and Choi, A. M. (2007). Mechanisms of cell death in oxidative stress. Antioxid. Redox Signal. 9, 49-89.

Saleem, R. (1995). Study of Chemical Constituents of Moringa Oleifera Lam. Ph.D. thesis, University of Karachi, Karachi.

Sashidhara, K. V., Rosaiah, J. N., Tyagi, E., Shukla, R., Raghubir, R., and Rajendran, S. M. (2009). Rare dipeptide and urea derivatives from roots of Moringa oleifera as potential anti-inflammatory and antinociceptive agents. Eur. J. Med. Chem. 44, 432-436.

Schneider, C., and Segre, T. (2009). Green tea: potential health benefits. Am. Fam. Physician 79, 591-594.

Siddhuraju, P., and Becker, K. (2003). Antioxidant properties of various solvent extracts of total phenolic constituents from three different agroclimatic origins of drumstick tree (Moringa oleifera Lam.) leaves. J. Agric. Food Chem. 51, 2144-2155.

Sniderman, A., McQueen, M., Contois, J., Williams, K., and Furberg, C. D. (2010). Why is non-highdensity lipoprotein cholesterol a better marker of the risk of vascular disease than low-density lipoprotein cholesterol? J. Clin. Lipidol. 4, 152-155.

Sreelatha, S., and Padma, P. R. (2009). Antioxidant activity and total phenolic content of Moringa oleifera leaves in two stages of maturity. Plant Foods Hum. Nutr. 64, 303-311.

Steinberg, D. (2002). Atherogenesis in perspective: hypercholesterolemia and inflammation as partners in crime. Nat. Med. 8, 1211-1217.

Stumvoll, M., Goldstein, B. J., and van Haeften, T. W. (2005). Type 2 diabetes: principles of pathogenesis and therapy. Lancet 365, 1333-1346.

Sudha, P., Asdaq, S. M., Dhamingi, S. S., and Chandrakala, G. K. (2010). Immunomodulatory activity of methanolic leaf extract of Moringa oleifera in animals. Indian J. Physiol. Pharmacol. 54, 133-140.

Sulaiman, M. R., Zakaria, Z. A., Bujarimin, A. S., Somchit, M. N., Israf, D. A., and Moin, S. (2008). Evaluation of Moringa oleifera aqueous extract for antinociceptive and anti-inflammatory activities in animal models. Pharmacol. Biol. 46, 838-845.
Thurber, M. D., and Fahey, J. W. (2009). Adoption of Moringa oleifera to combat under-nutrition viewed through the lens of the "diffusion of innovations" theory. Ecol. Food Nutr. 48, 212-225.

Torimiro, D. O., Odeyinka, S. M., Okorie, V. O., and Akinsuyi, M. A. (2009). Gender analysis of sociocultural perception of Moringa oeifera amongst farmers in southwestern Nigeria. J. Int. Womens Stud. 10, 188-202.

Tunnicliffe, J. M., Eller, L. K., Reimer, R. A., Hittel, D. S., and Shearer, J. (2011). Chlorogenic acid differentially affects postprandial glucose and glucose-dependent insulinotropic polypeptide response in rats. Appl. Physiol. Nutr. Metab. 36, 650-659.

van Dijk, A. E., Olthof, M. R., Meeuse, J. C., Seebus, E., Heine, R. J., and van Dam, R. M. (2009). Acute effects of decaffeinated coffee and the major coffee components chlorogenic acid and trigonelline on glucose tolerance. Diabetes Care 32, 1023-1025.

Verma, A. R., Vijayakumar, M., Mathela, C. S., and Rao, C. V. (2009). In vitro and in vivo antioxidant properties of different fractions of Moringa oleifera leaves. Food Chem. Toxicol. 47, 2196-2201.

WHO. (2003). Good Agricultural and Collection Practices (Gacp) for Medicinal Plants. Geneva: World Heath Organization.

Wild, S., Roglic, G., Green, A., Sicree, R., and King, H. (2004). Global prevalence of diabetes: estimates for the year 2000 and projections for 2030 . Diabetes Care 27, 1047-1053.

William, F., Lakshminarayanan, S., and Chegu, H. (1993). Effect of some Indian vegetables on the glucose and insulin response in diabetic subjects. Int. J. Food Sci. Nutr. 44, 191-196.

Yusuf, S., Reddy, S., Ounpuu, S., and Anand, S. (2001). Global burden of cardiovascular diseases: Part II: variations in cardiovascular disease by specific ethnic groups and geographic regions and prevention strategies. Circulation 104, 2855-2864.

Zhang, M., Swarts, S. G., Yin, L., Liu, C., Tian, Y., Cao, Y., Swarts, M., Yang, S., Zhang, S. B., Zhang, K., Ju, S., Olek, D. J. Jr., Schwartz, L., Keng, P. C., Howell, R., Zhang, L., and Okunieff, P. (2011). Antioxidant properties of quercetin. Adv. Exp. Med. Biol. 915, 283-289.

Zhang, X., Wang, W., and Xiao, K. (2010). "Novel omics technologies in neutraceutics and functional foodresearch," in Genomics, 
Proteomics, and Metabolomics in Nutraceuticals and Functional Foods, eds D. Bagchi, F. C. Lau, and M. Bagchi (Ames, IA: Wiley-Blackwell), $11-22$.

Conflict of Interest Statement: The author declares that the research was conducted in the absence of any commercial or financial relationships that could be construed as a potential conflict of interest.

Received: 05 October 2011; accepted: 08 February 2012; published online: 01 March 2012.
Citation: Mbikay M (2012) Therapeutic potential of Moringa oleifera leaves in chronic hyperglycemia and dyslipidemia: a review. Front. Pharmacol. 3:24. doi 10.3389/fphar.2012.00024

This article was submitted to Frontiers in Ethnopharmacology, a specialty of Frontiers in Pharmacology.
Copyright (C) 2012 Mbikay. This is an open-access article distributed under the terms of the Creative Commons Attribution Non Commercial License, which permits non-commercial use, distribution, and reproduction in other forums, provided the original authors and source are credited. 